\title{
Structure and strength of basal ice and substrate of a dry-based glacier: evidence for substrate deformation at sub-freezing temperatures
}

\author{
Sean J. Fitzsimons, ${ }^{1}$ Kevin J. MaManus, ${ }^{2}$ Reginald D. Lorrain ${ }^{3}$ \\ ${ }^{1}$ Department of Geography, University of Otago, P.O. Box 56, Dunedin, New Zealand \\ ${ }^{2}$ Department of Civil Engineering, University of Canterbury, Private Bag 4800, Christchurch, New Zealand \\ ${ }^{3}$ Département des Sciences de la Terre et de l'Environnement, Université Libre de Bruxelles, CP 160/02, B-1050, Brussels, Belgium
}

\begin{abstract}
This paper presents new data and interpretations of the structure, strength and behaviour of basal ice and the substrate of Suess Glacier, south Victoria Land, Antarctica, which is a small alpine dry-based glacier that has a basal temperature of $-17^{\circ} \mathrm{C}$. A tunnel excavated in the glacier revealed a substrate composed of frozen sand and gravel and a basal zone that was $3.8 \mathrm{~m}$ thick. From bottom to top, the basal zone was composed of $1.8 \mathrm{~m}$ of stratified, complexly deformed layers of ice and debris overlain by a $0.9 \mathrm{~m}$ thick layer of frozen sediment and a $0.8 \mathrm{~m}$ thick layer of discoloured ice lying immediately beneath clean glacier ice. Direct shear tests performed in the field on 36 samples show that the average peak shear strength of substrate samples was $2.53 \mathrm{MPa}$, which is almost twice as strong as the average value for basal ice (1.28 MPa) and the glacier ice samples $(1.39 \mathrm{MPa})$. The direct shear tests suggest that the glacier substrate is unlikely to deform at the current temperature. However, observations of the structure and composition of the basal zone suggest that the substrate contains localized weaknesses that may reduce the peak strength sufficiently to permit bed deformation and entrainment. Two observed forms of weakness are ice lenses and layers in the permafrost and lenses of unsaturated permafrost, which may be inherited from the active zone of a former land surface or produced as pore ice sublimes into cavities which have formed at the glacier bed. Interpretation of data from this study suggests that glacier beds well below the freezing point can be deformed and eroded under certain conditions.
\end{abstract}

\section{INTRODUGTION}

In reconstructing ice sheets and glaciers, geomorphologists tend to associate frozen-bed conditions with hiatuses in landform development during which no new landforms are created, with the exception of occasional glaciotectonic features (Kleman and Borgström, 1994; Kleman and Borgström, 1996). The underlying assumption of such studies is that glaciers that are frozen to their beds are largely incapable of erosion. However, theoretical studies by Shreve (1984) and Fowler (1986) concluded that sliding was possible at sub-freezing temperatures, and an empirical study by Boulton (1979) suggested that in some instances dry-based glaciers were capable of bed erosion. Subsequently, a study of the Ürümqi Glacier No. 1 (basal temperature $-5^{\circ} \mathrm{C}$ ) concluded that glacier movement was achieved by deformation of the substrate, movement along discrete shear planes within the frozen substrate or at the ice-substrate interface, and by basal sliding at ice-rock interfaces (Echelmeyer and Wang, 1987). Despite these theoretical and empirical studies, it is still relatively common to encounter studies that reject the possibility of basal sliding and erosion by dry-based glaciers. The apparent divergence in the geomorphological and glaciological literature requires attention if we are to make progress in the reconstruction of the thermal and dynamic conditions of former glaciers from glacial geological evidence. This paper describes an investigation of a small alpine glacier in the Taylor Valley, south Victoria Land, Antarctica that has a basal temperature of $-17^{\circ} \mathrm{C}$ (Fig. 1). Previous studies of Suess Glacier have shown that small

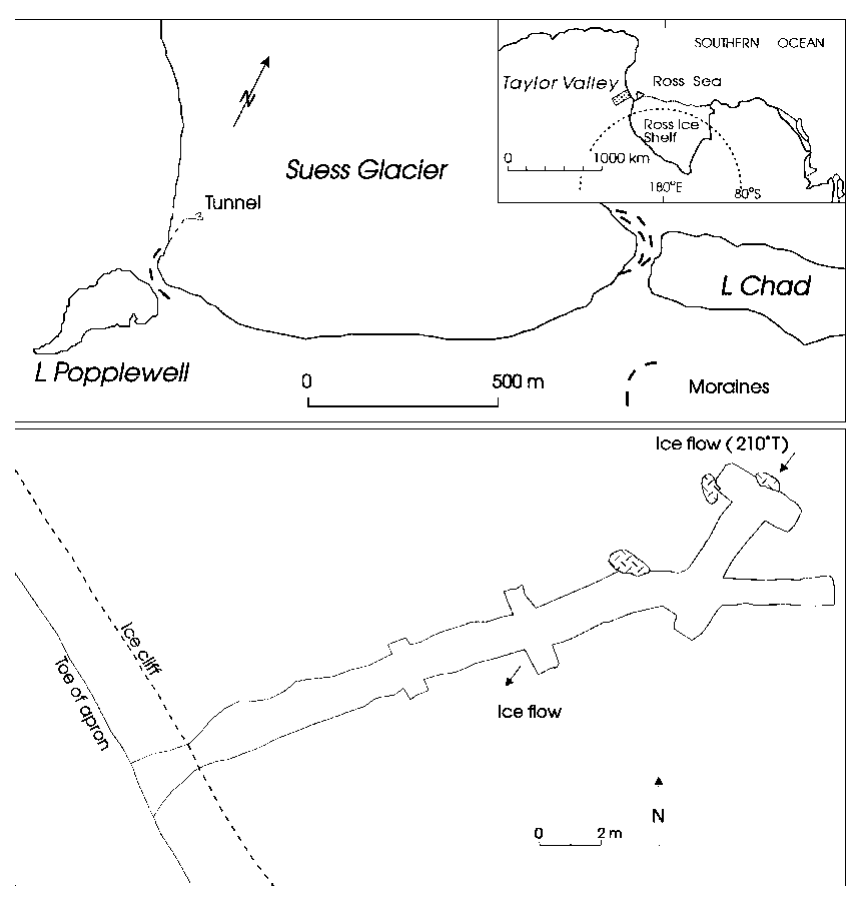

Fig. 1. Location map of tunnel and Suess Glacier. 
moraines occur around the glacier margin and that the basal zone is characterized by relatively thick laminated basal ice that contains large blocks of sediment (Fitzsimons, 1996). One hypothesis is that ice and debris was accreted to the sole of the glacier as it advanced into a proglacial lake (Fitzsimons, 1996). This hypothesis has been evaluated by examining the isotopic composition, solute chemistry and gas content of the ice exposed at the glacier margin (Lorrain and others, 1999). This paper describes a complementary study in which a tunnel was excavated upstream of the site studied by Lorrain and others (1999). Observations of basal ice in the tunnel suggest that the basal processes may be more complex than thought by examination of the ice margin alone. This study reports an investigation of subglacial erosion processes at low temperatures through observation of the ice-substrate interface, measurements of ice flow near the bed and experiments on the shear strength of glacier ice, basal ice and the glacier substrate.

\section{METHODS}

Suess Glacier is a small dry-based glacier that descends steeply from the Asgard Range onto the floor of Taylor Valley (Fig. 1). Although most of the glacier rests on gneiss, the terminus reaches the valley floor and rests on unconsolidated sediments that are frozen to a depth of more than $300 \mathrm{~m}$. The physical characteristics of the basal ice zone were observed at the foot of the ice cliff and by excavating a $2 \mathrm{~m} \times$ $1.51 \mathrm{~m} \times 25 \mathrm{~m}$ tunnel through the basal zone (Fig. 1). The tunnel was excavated over a period of two weeks using chainsaws with tungsten carbide bonded to the cutters. At the end of the right branch of the tunnel, a vertical shaft $4.5 \mathrm{~m}$ high was cut to expose the entire basal zone. Temperature measurements at the back of the tunnel, made with thermocouples and alcohol thermometers, showed that the temperature of the base of the glacier was $-17^{\circ} \mathrm{C} \pm 0.5^{\circ} \mathrm{C}$ during the six weeks from early December 1997 to late January 1998.

The velocity of the glacier at the bed was measured with linear variable displacement transducers (LVDTs) and precision dial gauges capable of measuring displacements of $0.01 \mathrm{~mm}$. Both the LVDTs and dial gauges were anchored to the substrate with rock bolts and were attached to the glacier using wooden pegs drilled and frozen into the ice $5 \mathrm{~mm}$ above the bed. LVDT displacements were recorded with a Campbell data logger and the dial gauges were read every two days for four weeks and after 348 days.

Plumb lines were used to characterize the form of the lower part of the velocity profile of the glacier by fixing a line with a plumb bob to a peg $2 \mathrm{~m}$ above a brass target bolted to the substrate. Displacements were measured as offsets from a vertical line of wooden pegs drilled and frozen into the ice at approximately $200 \mathrm{~mm}$ intervals, using digital callipers capable of recording distances $0.01 \mathrm{~mm}$. Movement of the bed was monitored at four locations in the tunnel by drilling a $400 \mathrm{~mm}$ hole and filling it with painted wooden dowel segments. The holes were excavated after 348 days and the positions of the dowel segments were measured.

The direct shear tests were conducted in the tunnel at a temperature of $-10 \pm 2{ }^{\circ} \mathrm{C}$ using a laboratory direct shear device modified for use in the field (Fig. 2). Cylindrical samples $59 \mathrm{~mm}$ in diameter and $130 \mathrm{~mm}$ in length were cored using a dry diamond core bit powered by an electric drill. The samples were frozen into place in the stainless steel plates of the shear box (Fig. 2) and a normal load was applied and adjusted using a pneumatic shock absorber, hand pump and a strain gauge. A normal load of $200 \mathrm{KPa}$ was used because this equates to the normal load of $20 \mathrm{~m}$ of ice at the site of the experiments. A displacement rate of $0.85 \mathrm{~mm} \mathrm{~h}^{-1}$ was used for the majority of the tests and most samples were sheared for 3-4 hours. Although this displacement rate is two orders of magnitude greater than basal zone velocities reported later in this paper, it was chosen to facilitate the measurement of a representative number of samples within the limited time of the field season. The shear strength was recorded as the output of a strain gauge that was logged every 61 seconds.

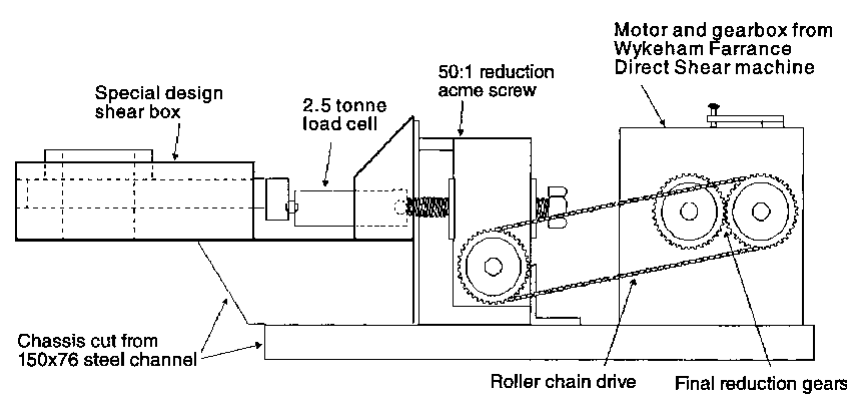

Fig. 2. Diagram of direct-shear device. Shear box is driven by an electric motor through a reduction screw. The shear strength is measured as the output of the 2.5 tonne load cell between the reduction screw and the shear box.

\section{STRUCTURE OF THE BASAL ZONE}

At the end of the tunnel, the basal zone is approximately $3.8 \mathrm{~m}$ thick and can be divided into five main units (Fig. 3) which include clean englacial ice $(0-0.3 \mathrm{~m})$, a discoloured ice facies $(0.3-1.1 \mathrm{~m})$, a solid layer of frozen sediment $(1.1-1.6 \mathrm{~m})$, a basal laminated facies (1.6-4.0 m) and the substrate (Fig. 3). The discoloured ice that rests immediately below the clean englacial ice contains dispersed particles and fine aggregates, which give the ice a greenish to amber colour. This ice is the "amber ice" that has been described as an important component of dry-based glaciers throughout the McMurdo Dry Valleys (Holdsworth, 1974). The amber ice is underlain by a broken layer of frozen sand and fine gravel that contains well-preserved sedimentary structures. This layer lies about $2 \mathrm{~m}$ above the glacier bed. The laminated ice that lies below the main debris band consists of multiple layers that range from near-horizontal, clean bubbly ice to complexly deformed layers of ice with very high debris concentrations. Occasional boulders up to $1.2 \mathrm{~m}$ in diameter were observed in the laminated ice up to $2 \mathrm{~m}$ above the bed. Ice with relatively low debris concentrations contained abundant ductile structures, whereas structures in the solid layers indicate predominantly brittle deformation. The bulk of the ductile deformation structures are tangential to the bed. Exposures of the substrate in the tunnel showed that the ice-substrate interface was a gently sloping (about $5^{\circ}$ ), smooth contact between basal ice and frozen sand. Particlesize analysis of the samples from the substrate showed that $75 \%$ of samples were polymodal. The most frequently occurring modes were centred on $1.5 \mathrm{~mm}$ (very coarse sand), $0.5 \mathrm{~mm}$ (coarse-medium sand) and $0.2 \mathrm{~mm}$ (fine sand). 


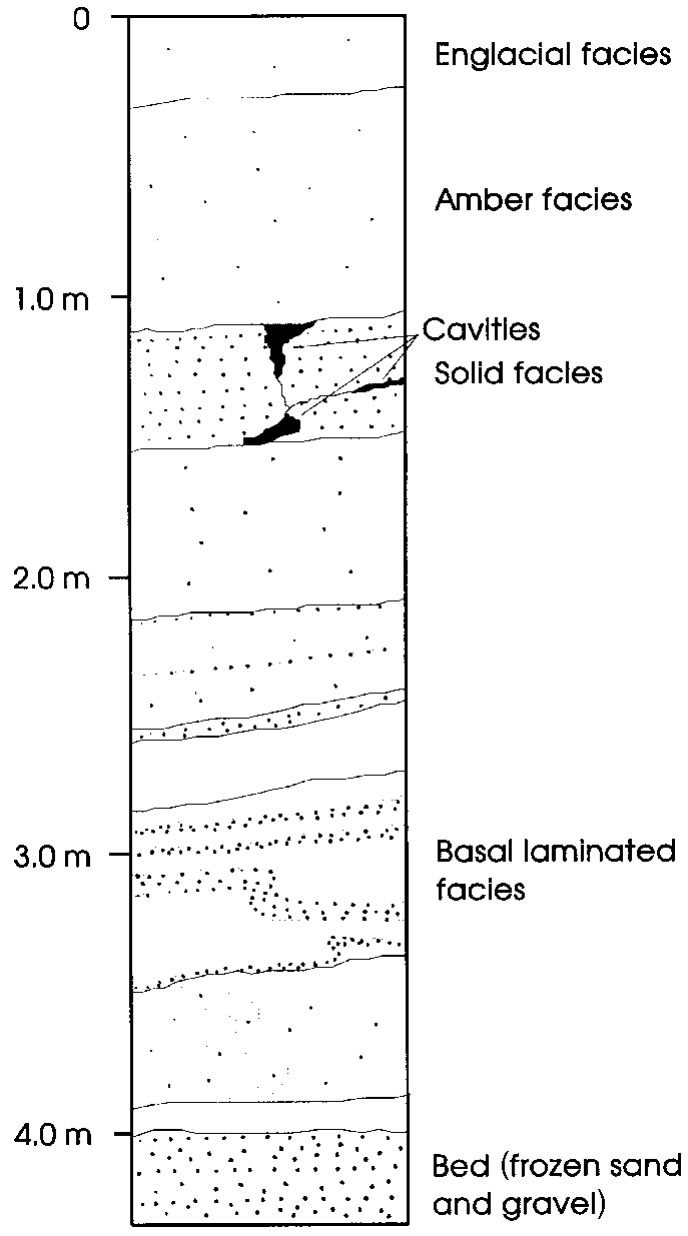

Fig. 3. The basal zone $24 \mathrm{~m}$ into the tunnel. Ice exposure shows five main units including clean englacial ice $(0-0.3 \mathrm{~m})$, a discoloured ice facies $(0.3-1.1 \mathrm{~m})$, a solid layer of frozen sediment $(1.1-1.6 \mathrm{~m})$, a basal laminated facies $(1.6-4.0 \mathrm{~m})$ and the substrate. Layers and structures within the basal zone dip in an upstream direction at angles between 3 and $10^{\circ}$.

Both the frozen sediment layer and the basal ice contain numerous cavities. The most widespread type of cavity occurs on the upstream and downstream sides of boulders and sediment blocks where ice flow around the obstacles has resulted in flow separations that have produced cavities up to $1 \mathrm{~m}$ long, $0.6 \mathrm{~m}$ wide and $300 \mathrm{~mm}$ high. Cavities also occur within the sediment band where blocks of frozen sediment have fractured, within relatively clean basal ice and at the ice-substrate interface. Several of the cavities contained gas at pressures slightly higher than atmospheric pressure.

Four conclusions can be drawn from observations of the basal zone exposed in the tunnel:

(1) Large blocks of sediment have been eroded from the frozen bed of the glacier.

(2) Many of the blocks in the basal ice have been entrained without disaggregation.

(3) Ice flow has elevated the main sediment layer about $2 \mathrm{~m}$ above the bed.

(4) The tunnel demonstrates that many of the proglacial structures observed around the margin of the glacier are similar to subglacial structures.

A previous interpretation of this glacier suggested that the moraines and some of the distinctive ice facies are the product of proglacial accretion of ice and debris as the gla- cier entered a proglacial lake (Fitzsimons, 1996; Lorrain and others, 1999). The observations described above suggest that entrainment of the sediment blocks and formation of the basal zone are more complex than thought by observation of the ice margin alone. It appears that entrainment of bed material has occurred in a subglacial position upstream from the end of the tunnel. If the material has been eroded from the bed, the key question is: how is the debris entrained? This is a significant problem because existing models that explain debris accretion and bed deformation depend on the temperature being close to or at pressure melting point (e.g. Weertman, 1961). Clearly, in the case of a glacier with a basal temperature of $-17^{\circ} \mathrm{C}$, these interpretations are inappropriate unless there is or has been liquid water beneath the glacier. The essence of the problem is that normally a glacier substrate is stronger than the overlying ice; therefore, the ice deforms rather than the glacier bed.

\section{ICE MOVEMENT AT THE BED}

Plumb lines recorded velocities around $80 \mathrm{~mm} \mathrm{a}^{-1}$ at $2 \mathrm{~m}$ above the bed to $6 \mathrm{~mm} \mathrm{a}^{-1} 50 \mathrm{~mm}$ above the bed (Fig. 4). Three LVDTs and four dial gauges mounted within $10 \mathrm{~mm}$ of the bed recorded no movement over a period of four months. Markers placed into four holes drilled into the bed to a depth of $500 \mathrm{~mm}$ recorded no displacement within the upper part of the bed after a period of 348 days.

The velocity measurements close to the bed show that sliding did not occur at the monitored locations during the four-month measurement period. Unusual patterns in the velocity profiles, such as shown by Figure 4, appear to be related to differences in the rheology of basal ice related to debris concentration and to flow separations within the basal zone. These data will be fully described in a future publication.

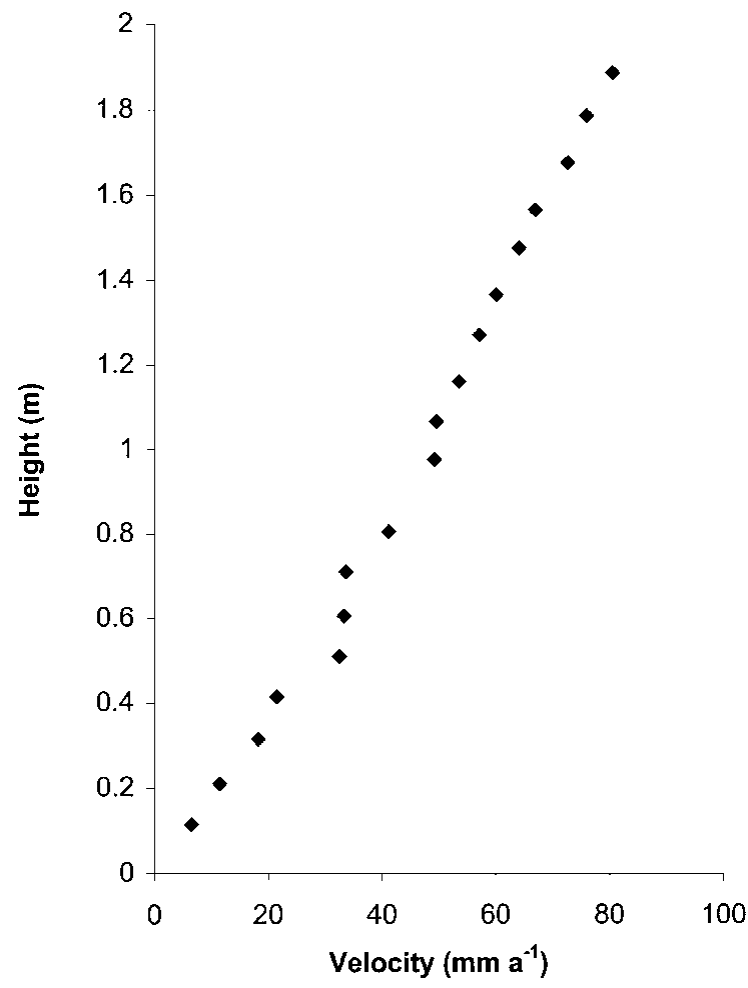

Fig. 4. Velocity profile measured using a plumb-line resurveyed after 348 days. 
Results of the direct shear tests are summarized in Table 1 and representative tests of amber, englacial and basal ice and the substrate are shown in Figure 5. Table 1 shows that the three amber ice samples have the lowest peak strength and least variability. These results are consistent with the work of Holdsworth (1974) and Holdsworth and Bull (1970), who recorded changes in rheology associated with increases in the dissolved solids in the amber ice. The clean englacial ice samples were slightly stronger than the amber ice samples and the stress-strain curves show that the strength of the samples did not decrease much after the peak strength was reached (Fig. 5b). Several tests of englacial ice samples produced stress-strain curves that have small steps in which the stress suddenly dropped about $0.06 \mathrm{MPa}$ (Fig. 5d). These steps may be related to the failure of small fracture planes oblique to the shear plane. The average peak strength of the basal ice samples is lower than that of the englacial ice samples. However, Table 1 shows there is an overlap in the strength characteristics and Figure 5 shows that the stressstrain curves for some basal ice samples are very similar to those of the englacial ice samples. Although the debris concentration in the 19 basal ice samples is highly variable, the standard deviation of the peak strength of these samples is lower than that of the englacial ice samples (Table 1). Most of the tests on the substrate samples recorded a significant decrease in strength after the peak strength was reached (Fig. 5d). In several cases, the rapid decline in post-peak strength is related to fracturing along the shear plane. Table 1 shows that the peak strength of the weakest substrate sample $(2.07 \mathrm{MPa})$ is very similar to the highest peak strength of the basal ice samples (2.04 MPa).

Two problems with the direct shear tests need to be con-

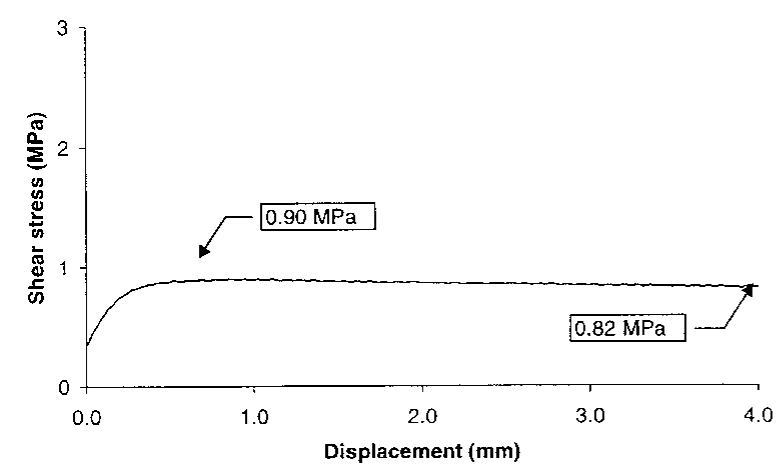

a

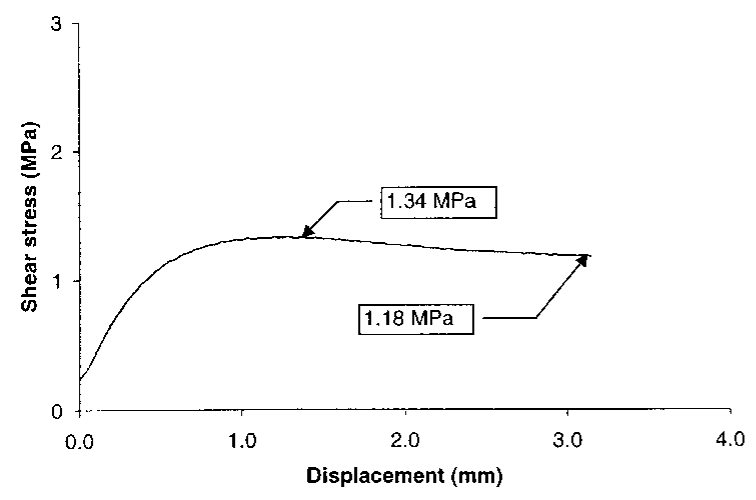

Table 1. Peak shear-strength values from direct-shear tests

\begin{tabular}{lccccc}
\hline Material & $\begin{array}{c}\text { Number of } \\
\text { samples }\end{array}$ & Max. & $\begin{array}{c}\text { Peakstrength } \\
\text { Min }\end{array}$ & Mean & std dev. \\
\hline Amber ice & 3 & 1.06 & 0.73 & 0.9 & 0.17 \\
Englacial ice & 6 & 1.75 & 0.79 & 1.39 & 0.31 \\
Basal ice & 19 & 2.04 & 0.94 & 1.28 & 0.27 \\
Substrate & 8 & 3.29 & 2.07 & 2.53 & 0.35 \\
& & & & & \\
\hline
\end{tabular}

sidered. First, the direct-shear device imposes the orientation and location of the shear plane because the cylindrical sample is placed in a hole drilled in two stainless-steel plates. The shear plane is defined by the contact between the two sliding plates and the relationship between the thickness of the bottom plate and the length of the sample. Cutting the samples perpendicular to the structural fabric of the materials and careful alignment of structures and layers with the shear plane provides a partial solution to this difficulty. However, the complex and highly variable structure of the ice means that in some cases it is likely the device is shearing across existing structural elements in the materials that might define layers that have different creep rates. For example, some of the substrate samples contained lenses and layers of segregated ice, which might be significantly weaker than the material in which the ice is confined to the pores. Similarly, the basal ice contains multiple layers of variable thickness and debris concentrations. Given these problems, the shearstrength data should be regarded as providing estimates of the bulk strength properties of the samples.

A second problem associated with the direct shear tests is that, in order to test a representative number of samples, a

C

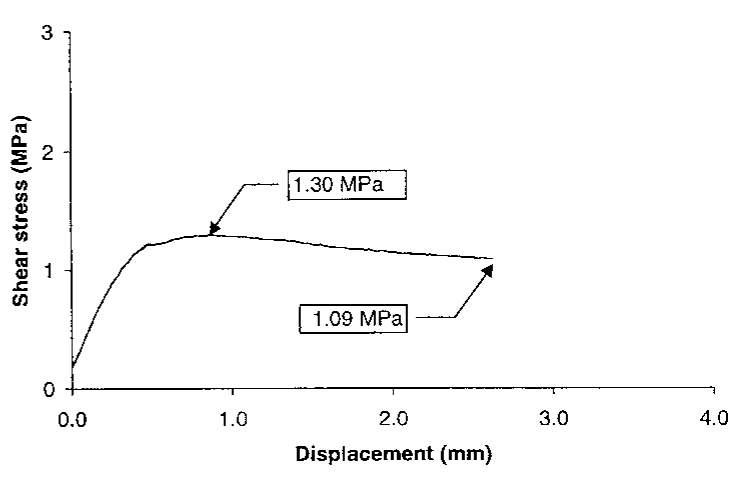

b

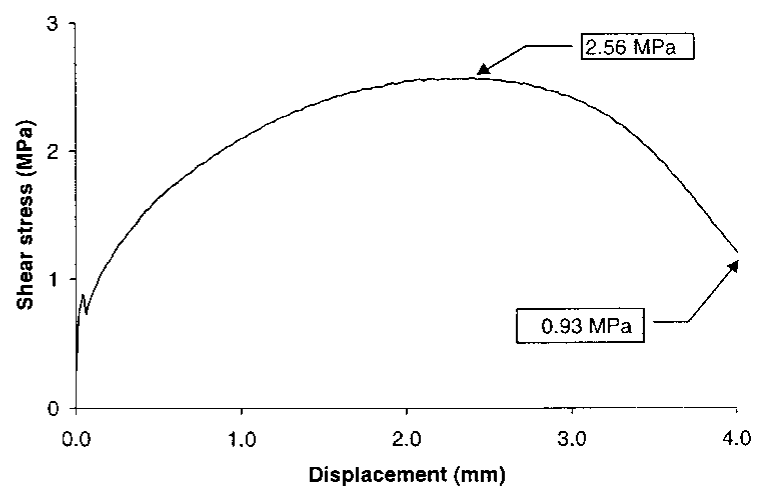

d

Fig. 5 Representative stress-strain curves: (a) amber ice (b) clean glacier ice, (c) basal ice and (d) substrate. 
load rate of $0.85 \mathrm{~mm} \mathrm{~h}^{-1}$ was used. This load rate is considerably greater than the velocities experienced at the base of the glacier $\left(20 \mathrm{~mm} \mathrm{~d}^{-1}\right.$ vs $\left.0.23 \mathrm{~mm} \mathrm{~d}^{-1}\right)$. It is possible that the strong peak in the strength of the substrate may be substantially lower if the tests are conducted at more realistic strain rates.

\section{DISCUSSION}

Taken at face value, the direct shear tests suggest that on average the glacier substrate is unlikely to deform at present because the substrate has about twice the strength of the glacier ice. However, the strengths of some of the substrate samples are not significantly greater than some of the glacial ice and basal ice samples (Table 1). Relatively small changes in strength might result in the substrate yielding at the same or lower stresses than the basal ice. Research on subglacial sediment deformation provides a useful framework for interpretation of the data presented above. Boulton's (1996) theoretical model emphasizes the alteration of shear strength of materials as pore-water pressures fluctuate. This analogy is useful because it leads to the question: how can the shear strength of materials be altered in the system described above? On the basis of observations made in the tunnel, it is possible to identify two potential sources of variation:

(1) The strength of the substrate may be reduced because of the presence of cavities.

(2) The substrate may contain or develop structural weaknesses.

Where cavities have formed adjacent to the substrate or sediment blocks within the basal zone, the bottoms of the cavities contain accumulations of loose sand and gravel which are the product of sublimation of the ice matrix. Attempts to test the strength of the substrate without pore ice failed because the samples disintegrated when the corer encountered the sediment that did not contain ice. However, the outcome of sublimation is clearly that the strength of the material is dramatically reduced because the cohesion produced by the pore ice is lost. It seems likely that the formation of a cavity can lead to localized weakening of the sediment, fracture and dislodgement.

Two potential forms of structural variation that have been observed in the substrate or in blocks of sediment entrained in the basal ice are thin mud layers and segregated ice layers. All the observed layers of mud and ice were less than $5 \mathrm{~mm}$ thick and therefore too small to position accurately in the direct shear device. Although this study has not produced any data on the strength characteristics of the mud layers, the data described above show that the peak shear strength of the ice samples is less than that of the frozen sand of the substrate samples (Fig. 5). As ice content increases above saturation, the shear strength of the material decreases because of the reduction in internal friction as the individual particles are separated by ice (Nickling and Bennett, 1984). It is likely that frozen debris resting between deforming basal ice and a moving ice layer would be entrained.

\section{GONCLUSIONS}

Observations in the tunnel of the structure and sedimentol- ogy of the basal zone show that parts of it are derived from the bed. These observations suggest that many features observed at the ice margin are extensions of subglacial structures and that entrainment processes in Suess Glacier are more complex than previously thought. Measurements of the movement of the lower part of the basal zone suggest that the glacier is not sliding and the bed is not deforming at the monitored locations at present, or the movement is so slight that it is not detectable. Direct shear strength tests of clean ice, debris-laden ice and the bed material show that the average peak strength of the substrate is considerably greater than that of debris-bearing and clean ice. However, there is almost an overlap in the strength of the samples that were tested. Although we conclude that the substrate is not likely to deform under the present conditions, relatively minor variations in the strength of the substrate would result in bed deformation. Observations of the structure of the basal zone and substrate suggest two possible mechanisms. First, the formation of cavities allows the ice matrix of frozen debris to sublime, which is likely to produce localized variations in strength. Second, segregated ice layers and lenses within the substrate and close to the glacier sole may creep and lead to the deformation and failure of the substrate between two layers of deforming ice. Although the results of this study do not provide a certain interpretation of the bed deformation and entrainment processes, the study suggests that dry-based glaciers are capable of significant erosion in some circumstances.

Triaxial tests with a low strain rate should overcome the problems associated with the direct-shear technique and analysis of the composition of basal ice in the tunnel may clarify the origin of the basal ice layers.

\section{REFERENGES}

Boulton, G. S. 1979. Processes of glacier erosion on different substrata. F. Glaciol., 23(89), 15-38.

Boulton, G. S. 1996. Theory of glacial erosion, transport and deposition as a consequence of subglacial sediment deformation. F. Glaciol., 42(140), 43-62.

Echelmeyer, K. and Wang Zhongxiang. 1987. Direct observation of basal sliding and deformation of basal drift at sub-freezing temperatures. $\mathcal{F}$. Glaciol., 33(113), 83-98.

Fitzsimons, S. J. 1996. Formation of thrust-block moraines at the margins of dry-based glaciers, south Victoria Land, Antarctica. Ann. Glaciol., 22, 68-74.

Fowler, A. C. 1986. Sub-temperate basal sliding. F. Glaciol., 32(110), 3-5.

Holdsworth, G. 1974. Meserve Glacier, Wright Valley, Antarctica: Part 1. Basal processes. Ohio State Univ. Inst. Polar Stud. Rep. 37.

Holdsworth, G. and C. Bull. 1970. The flow law of cold ice: investigations on Meserve Glacier, Antarctica. International Association of Scientific Hydrology Publication 86 (Symposium at Hanover 1968 - Antarctic Glaciological Exploration (ISAGE)), 204-216.

Kleman, J. and I. Borgström. 1994. Glacial land forms indicative of a partly frozen bed. F. Glaciol., 40 (135), 255-264.

Kleman, J. and I. Borgström. 1996. Reconstruction of palaeo-ice sheets: the use of geomorphological data. Earth Surf. Processes Landforms, $21(10), 893-909$.

Lorrain, R. D., S. J. Fitzsimons, M. J. Vandergoes and M. Stiévenard. 1999. Ice composition evidence for the formation of basal ice from lake water beneath a cold-based Antarctic glacier. Ann. Glaciol., 28 (see paper in this volume).

Nickling, W. G. and L. Bennett. 1984. The shear strength characteristics of frozen coarse granular debris. F. Glaciol., 30(106), 348-357.

Shreve, R. L. 1984. Glacier sliding at subfreezing temperatures. F. Glaciol., 30(106), 341-347.

Weertman, J. 1961. Mechanism for the formation of inner moraines found near the edge of cold ice caps and ice sheets. F. Glaciol., 3(30), 965-978. 